\title{
C-Arm Computed Tomography Adds Diagnostic Information in Patients with Chronic Thromboembolic Pulmonary Hypertension and a Positive V/Q SPECT \\ Chronisch thromboembolische pulmonale Hypertonie: Diagnostischer Zusatznutzen der pulmonalarteriellen C-Arm-CT bei Patienten mit positivem V/Q SPECT
}

Authors

Jan B. Hinrichs ${ }^{1}$, Thomas Werncke ${ }^{1}$, Till Kaireit ${ }^{1}$, Marius M. Hoeper ${ }^{2}$, Karen M. Olsson², Jan-Christopher Kamp², Frank K. Wacker ${ }^{1}$, Frank Bengel ${ }^{3}$, Christian von Falck', Imke Schatka ${ }^{3,4}$, Bernhard C. Meyer ${ }^{1}$

\section{Affiliations}

1 Department for Diagnostic and Interventional Radiology, Member of the German Center for Lung Research (DZL), Hannover Medical School, Hannover, Germany

2 Clinic for Pneumology, Member of the German Center for Lung Research (DZL), Hannover Medical School, Hannover, Germany

3 Department of Nuclear Medicine, Hannover Medical School, Hannover, Germany

4 Department of Nuclear Medicine, Charité-University Medicine Berlin, Germany

Key words

cone-beam computed tomography, chronic thromboembolic pulmonary hypertension, CTEPH, SPECT, lung perfusion, radiation exposure pulmonary CACT

received 9.6.2016

accepted 19.8.2016

\section{Bibliography}

DOI http://dx.doi.org/10.1055/s-0042-116232

Published online: 26.10.2016 | Fortschr Röntgenstr 2017; 189: 49-56

(c) Georg Thieme Verlag KG Stuttgart · New York

ISSN 1438-9029

Correspondence

Dr. Jan B Hinrichs

Diagnostische und Interventionelle Radiologie, Medizinische Hochschule Hannover

Carl-Neuberg-Straße 1

30625 Hannover

Germany

Tel.: ++ 49/511/5323421

Fax: $++49 / 511 / 5329421$

hinrichs.jan@mh-hannover.de

\section{ZUSAMMENFASSUNG}

Ziele Evaluation der potentiellen diagnostischen Zusatzinformationen der pulmonalarteriellen C-Arm CT (CACT) bei Patienten mit chronisch thromboembolischer pulmonaler Hypertonie (CTEPH) und positivem Ventilations-/ Perfusions-Mismatch in der Einzelphotonen-Emissionscomputertomografie (V/Q SPECT).
Material und Methoden 28 Patienten (23 Männer, 5 Frauen, $62 \pm 18$ Jahre) mit CTEPH wurden mittels SPECT, CACT und Rechtsherzkatheter (RHK) untersucht. Die SPECT und die CACT wurden von zwei unabhängigen Untersuchern beurteilt. Beide Untersuchungsmodalitäten wurden nach CTEPH-typischen Befunden ausgewertet, die Lokalisation der Befunde wurde bestimmt (segmental, sub-segmental) und mittels 3-Punktskala bewertet (pulmonary artery CTEPH severity score (PACSS)). Die Übereinstimmung der Modalitäten wurde berechnet (Cohen's Kappa). Die Summe des PACSS wurde für jede Bildgebungsmodalität berechnet und mit der dem RHK korreliert (Spearman Korrelation). Außerdem wurde der PACSS mit der Therapieentscheidung des CTEPH-Boards verglichen (Grundlage: SPECT, selektive DSA und CACT).

Ergebnisse Insgesamt wurden 504 Pulmonalarteriensegmente in beiden Modalitäten untersucht. Die SPECT hat 266/504 (53\%) Segmente ohne Perfusionsausfälle und 238/504 (47\%) mit Perfusionsausfällen bewertet. Die CACT hat 131/504 (26\%) Segmente ohne CTEPH-typische Befunde bewertet, in 373/504 (74\%) Segmenten wurden CTEPH-typische Befunde erhoben. Die Übereinstimmung der Modalitäten hinsichtlich pathologischer Befunde war

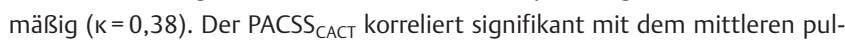
monalarteriellen Druck ( $r h o=0,48, p=0,01$ ), wohingegen der PACSS SPECT $_{\text {. }}$ keine signifikante Korrelation zeigt ( $r h o=0,32, p=0,1)$. Die Abweichungen zwischen beiden Methoden sind hauptsächlich mit der höheren Detektionsrate der CACT von sub-segmentalen CTEPH-typischen Befunden zu erklären, diese wurden in der SPECT als normal bewertet.

Schlussfolgerung Die kontrastmittelverstärkte CACT weist im Vergleich zur SPECT zusätzliche CTEPH-typische Befunde mit einer besseren Korrelation zum pulmonalarteriellen Mitteldruck nach. Im Vergleich zur CACT unterschätzt die SPECT das Ausmaß und die Komplexität der vaskulären Befunde bei Patienten mit CTEPH.

\section{Kernaussagen}

- Die CACT hat einen zusätzlichen Nutzen bei CTEPH-Patienten mit positivem V/Q SPECT.

- Die SPECT kann das Ausmaß der CTEPH unterschätzen.

- Die CACT detektiert Befunde in Pulmonalarterien, die im V/Q SPECT keinen Befund aufweisen.

\section{ABSTRACT}

Purpose To determine if C-Arm computed tomography (CACT) has added diagnostic value in patients suffering from chronic thromboembolic pulmonary hypertension (CTEPH) with a positive mismatch pattern in ventilation/perfusion single photon emission computed tomography (V/Q SPECT).

Materials and Methods 28 patients ( 23 men, 5 women, $62 \pm 18$ years) with CTEPH who had undergone SPECT, followed by CACT and right heart catheterization (RHC) were included. Two independent readers reviewed SPECT and CACT. Findings indicating CTEPH and their location (segmental or subsegmental) were identified (V/Q mismatch in SPECT and vascular pathologies in CACT). Inter-modality agreement was calculated (Cohen's Kappa). Findings were scored on a 3-point-scale. The sum of the score (pulmonary artery 
CTEPH severity score (PACSS)) was calculated for each patient and imaging modality, correlated to RHC (spearman's correlation) and compared to the final therapeutic decision of the CTEPH board (including the consensus of SPECT, selective pulmonary DSA and CACT).

Results Overall, 504 pulmonary artery segments were assessed in SPECT and CACT. SPECT had identified 266/504 (53\%) arterial segments without and 238/504 (47\%) segments with a V/Q mismatch indicating CTEPH. CACT detected $131 / 504(26 \%)$ segments without abnormal findings and 373/504 (74\%) segments with findings indicating CTEPH. Inter-modality agreement was fair $(\mathrm{K}=0.38)$. PACSS of CACT correlated mildly significantly with the mean pulmonary artery pressure (PAPmean; rho $=0.48, p=0.01$ ), while SPECT missed significance ( $r$ o $=0.32, p=0.1$ ). Discrepant findings were mostly attributed to a higher frequency of sub-segmental pulmonary arterial pathologies on CACT (145 sub-segmental findings indicating CTEPH) rated as normal on SPECT.
Conclusion In patients with CTEPH, contrast-enhanced CACT detects additional findings with a better correlation to the severity of PAPmean than V/Q SPECT. CACT indicates abnormalities even in segments without V/Q abnormalities.

\section{Key points}

- CACT has additional value in V/Q SPECT-positive CTEPH patients.

- SPECT may underestimate the extent of CTEPH.

- CACT indicates abnormalities even in segments without V/Q abnormalities.

\section{Citation Format}

- Hinrichs JB, Werncke T, Kaireit T et al. C-Arm Computed Tomography Adds Diagnostic Information in Patients with Chronic Thromboembolic Pulmonary Hypertension and a Positive V/Q SPECT. Fortschr Röntgenstr

\section{Introduction}

Chronic thromboembolic pulmonary hypertension (CTEPH) is a severe complication of an acute pulmonary embolism, with a reported incidence of $0.1-9 \%$ [ $1-3]$. Due to the increasing diversity of treatment options, e. g. surgery, balloon pulmonary angioplasty (BPA), and medical therapy, the accurate determination of the anatomical extent of the disease and the precise detection and characterization of the thrombotic material in the pulmonary vasculature become increasingly important [2, 4-6]. Today, surgical pulmonary endarterectomy (PEA) is still the treatment of choice [2]. However, up to $40 \%$ of all CTEPH patients are inoperable, mainly due to a peripheral location of their vascular pathologies $[1,6]$. Medical treatment and the recently emerging BPA technique represent therapeutic options for inoperable patients $[2,7]$. BPA can be used to treat peripheral, web-like stenoses and intraluminal bands in small, sub-segmental branches of the pulmonary arteries with encouraging treatment results [2, 6, 7].

The assessment and detection of regional perfusion defects is indispensable for establishing the diagnosis of CTEPH $[1,2,6]$. Single photon emission computed tomography (SPECT) perfusion lung scintigraphy is a standard tool for the detection of perfusion defects in patients with suspected CTEPH $[2,4]$. In patients who are highly suspicious for CTEPH, digital subtraction angiography (DSA) represents a standard method for verifying the diagnosis and for imaging morphological alterations of the pulmonary vasculature for further treatment planning [6]. However, DSA suffers from the limitations inherent to a projectional imaging technique. Due to recent technical advances, intra-arterial contrast-enhanced $\mathrm{C}$-arm CT (CACT) of the pulmonary arteries can be acquired in conjunction with DSA [8, 9]. Local contrast administration in the main pulmonary artery allows the acquisition of an isolated pulmonary arterial contrast phase $[8,9]$. As a true crosssectional modality, CACT has been shown to provide a more detailed and comprehensive CTEPH imaging work-up, especially with regard to the characterization of CTEPH findings [8 - 11].

Despite the well-established role of SPECT in the initial work-up of CTEPH for the detection of the disease, some studies suggest limitations of SPECT when it comes to CTEPH characterization on a segmental and sub-segmental basis [4, 12]. The purpose of our study is to provide insight into the added diagnostic value of C- arm computed tomography for patients suffering from CTEPH with a positive mismatch pattern in ventilation/perfusion (V/Q) SPECT.

\section{Materials and Methods}

Our hospital's Institutional Review Board approved this retrospective study. The diagnostic evaluation of patients with suspected CTEPH at our institution follows a standard protocol based on current guidelines [6]. Patients with clinically suspected CTEPH are referred to the Department of Nuclear Medicine for SPECT imaging. A suspicious SPECT with ventilation/perfusion mismatches indicative of CTEPH is followed by DSA combined with contrast-enhanced CACT in order to confirm the diagnosis $[2,6,13]$. Invasive imaging is combined with right heart catheterization using the same venous access $[8,14]$. Therefore, our study reflects the current guidelines for CTEPH and represents the clinical routine [6].

During the study period from June 2013 to July 2014, 97 patients (54 men, 43 women; $64 \pm 14$ years of age) with suspected CTEPH underwent the aforementioned imaging work-up. The inclusion criteria for this study were as follows: acquisition of SPECT and CACT in the same patient in our institution within a maximum of 14 days between both examinations; and diagnosis of CTEPH by right heart catheterization and imaging studies [6]. Patients with a history of lung surgery or pulmonary congenital abnormalities or with combined V/Q defects were excluded from our study. Finally, 28 patients (23 men, 5 women, mean age $62.1 \pm 17.8$ years) met the inclusion criteria.

\section{SPECT image acquisition}

Pulmonary scintigraphy included a perfusion and ventilation SPECT. SPECT imaging was performed on a Symbia T2 (Siemens Healthcare, Forchheim, Germany) with the patient in a supine position. In SPECT mode, 64 projections (matrix: $128 \times 128$ ) were acquired in one bed position on a $360^{\circ}$ trajectory. The acquisition time per projection was $20 \mathrm{~s}$ for ventilation and $10 \mathrm{~s}$ for perfusion. Iterative reconstruction was performed using ordered subsets expectation maximization (OSEM) with four subsets and eight iterations.

Ventilation scans were acquired after inhalation of $200 \pm 6 \mathrm{MBq}$ Tc-99m-technegas over $3-6$ respiratory cycles, prepared in a 
generator (Technegas Generator, Tetley Manufacturing Ltd, Sydney, Australia), and of which approximately 20 - $40 \mathrm{MBq}$ accumulated in the lung. Immediately thereafter, perfusion studies were performed after intravenous injection of $200 \pm 13 \mathrm{MBq}$ of Tc-99mlabelled human serum albumin microspheres (ROTOP Pharmaka $\mathrm{GmbH}$, Dresden, Germany). The geometric resolution of the SPECT camera is $6.4 \mathrm{~mm}$.

\section{Image analysis of SPECT scans}

Anonymized images of SPECT lung scans were interpreted by one clinically experienced nuclear medicine physician (I.S. with five years of clinical experience in lung imaging) who was unaware of the angiographic data. Planar images were not analyzed for this study. Pulmonary artery segments were assessed using a standardized segmental lung reference chart according to the Boyden nomenclature [15]. In brief, the pulmonary arteries were subdivided into 18 pulmonary artery segments (PAS): 10 right lung (RA), 8 left lung (LA) per patient.

The perfusion images were interpreted in conjunction with the ventilation images. A perfusion defect was identified as a characteristic V/Q mismatch, i. e. reduced perfusion associated with normal ventilation, within a pulmonary artery segment. Patients with combined perfusion/ventilation defects were excluded from this study. The segmental CTEPH finding score for perfusion/ventilation mismatches was assigned based on a 3-point scale for each of the 18 segments as follows: $0=$ no perfusion defect; 1 = subsegmental perfusion defects; 2 = segmental perfusion defects.

\section{C-arm computed tomography image acquisition}

Following positive SPECT, invasive imaging, including contrast-enhanced CACT of the pulmonary arteries, was acquired on a monoplane, ceiling-mounted angiographic system equipped with a $30 \times 40 \mathrm{~cm}$, flat-panel detector (Artis $\mathrm{Q}^{\circledR}$, Siemens Healthcare, Forchheim, Germany). A 5 F pigtail catheter (Optitorque ${ }^{\circledR}$, Terumo Europe, Leuven, Belgium) was placed in the pulmonary trunk and contrast agent was administered using a dual-barrel injector (Accutron HP-D, Medtron AG, Saarbrücken, Germany) within a single modest inspiratory breath-hold (total injected volume $70 \mathrm{~mL}$, comprising $49 \mathrm{~mL}$ lomeprol $300 \mathrm{mgl} / \mathrm{mL}$ and $21 \mathrm{~mL}$ saline solution, effective iodine concentration $210 \mathrm{mgl} / \mathrm{mL}$, flow rate $8 \mathrm{~mL}$ / s) [8]. A standard preset (6s DR DynaCT $\left.{ }^{\circledR}\right)$ was applied. For each patient one CACT with central contrast injection in the main pulmonary artery was acquired. The CACT dataset with an isotropic voxel size of $(0.4 \mathrm{~mm})^{3}$ was computed on a dedicated workstation (syngo X Workplace ${ }^{\circledR}$ VD10A, Siemens Healthcare).

\section{Image analysis of CACT images}

CACT images were anonymized and assessed by one qualified interventional radiologist (J.B.H. with five years of clinical experience in cardiovascular and interventional radiology) and who was unaware of the SPECT data. Pulmonary artery segments were assessed using the same standard reference chart as described above [15]. The reader recorded the location of segmental or sub-segmental findings suggestive of the presence of thromboembolic material or residuals in the pulmonary arteries, such as wall-adherent thrombotic material, intraluminal or eccentric filling defects, abrupt changes in vessel caliber, post-stenotic dila- tations, intraluminal webs and bands, luminal narrowing and complete occlusions. For assessment of the CACT images and detection of the pathologic CACT findings, the reader was allowed to use average intensity projections (AvIP), thin-slice MPR, and MIP in any orientation at his own discretion. The slice thickness of the MIP images was interactively adjusted if necessary in order to optimize image interpretation. A segmental CTEPH finding score was assigned based on a 3-point scale for each of the $18 \mathrm{seg}$ ments as follows: $0=$ pulmonary artery segments without signs of CTEPH with preserved patency; 1 = sub-segmental defects of the pulmonary artery patency, e.g. partial obstruction, webs, and bands causing sub-segmental filling defects; and 2 = complete obstruction with segmental loss of pulmonary artery patency. Substantial motion artifacts impairing CACT image analysis with regard to findings indicating CTEPH were not detected.

\section{Diagnostic right-heart catheterization}

Right-heart catheterization was performed immediately before invasive imaging. A jugular or femoral venous access was established using an 8 French (F) introducer sheath (Avanti+, Cordis, Waterloo, Belgium), and a 7F Swan-Ganz catheter (Edwards Lifesciences, Unterschleissheim, Germany) was then inserted. Standard right-heart catheterization measurements were performed, including the mean pulmonary-artery pressure $\left(\mathrm{PAP}_{\text {mean }}\right)$. The pulmonary vascular resistance (PVR; dyn ${ }^{*} \mathrm{~s} / \mathrm{cm}^{5}$ ) was calculated.

\section{Radiation exposure}

The mean effective radiation dose for CACT was assessed using 100 thermoluminescence detectors (TLD-100H; Thermo Fisher Scientific, Waltham, MA) in an anthropomorphic, radio-equivalent, whole-body phantom (adult male phantom, model 701, CIRSinc, Norfolk, VA, USA), as described in the literature [16], in order to elucidate the potential differences in radiation exposure. The mean effective dose was computed according to the recommendations of the International Commission on Radiological Protection Publication 103 [17]. The total uncertainty of the radiation dose measurements was estimated to be $7 \%$.

\section{Data evaluation and statistical analysis}

Descriptive statistical analyses of the patient demographics, rightheart catheterization, SPECT, and CACT data were calculated.

To assess a pulmonary artery CTEPH severity score (PACSS) for

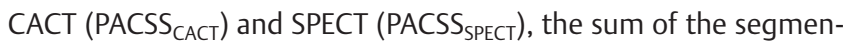
tal CTEPH finding score for each modality was computed (range from $0=$ no findings in all 18 segments to $36=$ occlusion of all 18 segments). Each patient was assigned to either conservative or invasive treatment by the CTEPH Board whose decision was based on a consensus including the SPECT imaging findings and invasive imaging as well as the clinical parameters and right heart hemodynamics. The overall correlation of PACSS CACT $_{\text {and PACSS }}$ SPECT was calculated (Spearman's rank correlation coefficient: $\rho$ ) in order to describe their agreement. The median overall PACSS ${ }_{\text {CACT }}$ and PACSS $_{\text {SPECT }}$ were compared using the pairwise Wilcoxon signedrank test. The median PACSS dependent on the treatment decision was compared for each modality using the Mann-Whitney U-Test. Moreover, the PACSS assessed by each modality was correlated (Spearman's rank correlation coefficient: $\rho$ ) to the right-heart ca- 


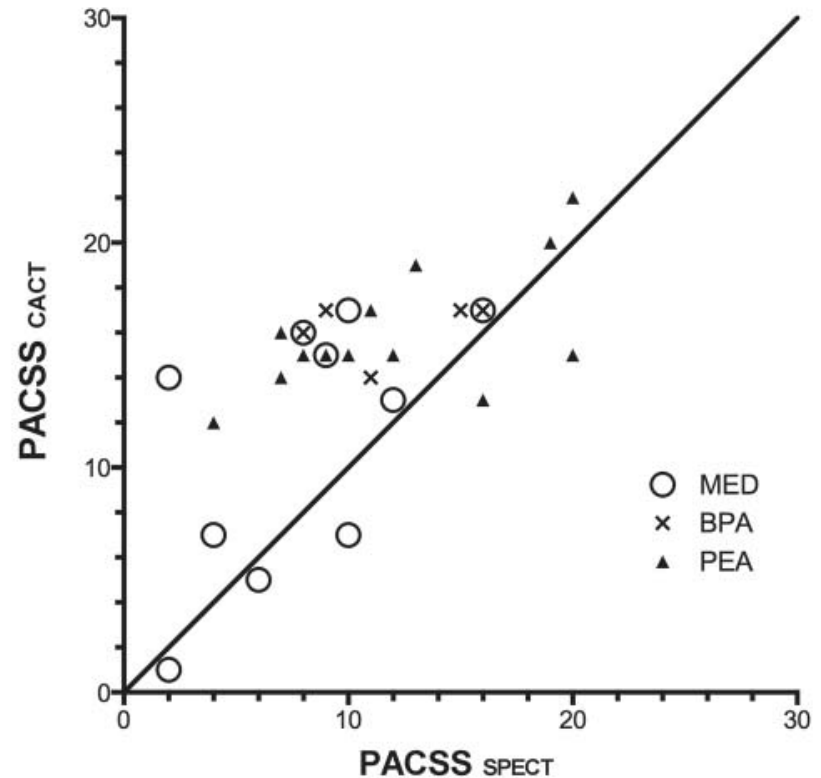

- Fig. 1 PACSS of SPECT vs. CACT and therapeutic decision of the CTEPH board. Pulmonary artery CTEPH severity score (PACSS) between both modalities showing more findings in CACT. Shown are the calculated PACSS of the abnormal imaging findings in SPECT compared to CACT in the 28 investigated patients. CACT was able to detect more findings compared to SPECT. CACT $=\mathrm{C}$-arm computed tomography; SPECT = single photon emission computed tomography; MED = medical therapy; BPA = balloon pulmonary angioplasty; PEA = pulmonary endarterectomy.

- Abb. 1 PACSS von SPECT und CACT und therapeutische Entscheidung des CTEPH-Boards. Vergleich des „Pulmonary Artery CTEPH Severity Score“ (PACSS) zwischen beiden Modalitäten mit Nachweis von mehr Befunden in der CACT. In der Grafik sind die berechneten PACSS der CTEPH-typischen Befunde von SPECT und CACT zum Vergleich dargestellt. Die CACT hat mehr Befunde detektiert als die SPECT. CACT = C-Arm-Computertomografie; SPEC$\mathrm{T}=$ Einzelphotonen-Emissionscomputertomografie; $\mathrm{MED}=$ konser vative Therapie mit Medikamenten; $\mathrm{BPA}=$ pulmonale Ballonangioplastie; PEA = pulmonale Endarteriektomie; BPA und PEA zusammen sind die invasive Therapiegruppe.

theterization pressure measurements reflecting a clinical CTEPH severity parameter [18]. Cohen's kappa (к) was calculated in order to determine the inter-modality agreement of the segmental CTEPH finding score for SPECT and CACT. The interpretation of kappa followed previously published guidelines [19].

A p-value of 0.05 was defined as the level of statistical significance. Statistical analyses were conducted using commercially available software (JMP 11, SAS Institute, JMP Office Germany, Böblingen, Germany). Demographic data and right-heart catheter measurements are presented as mean \pm standard deviation. Calculated values of PACSS are given as median and 25/75 interquartile range.
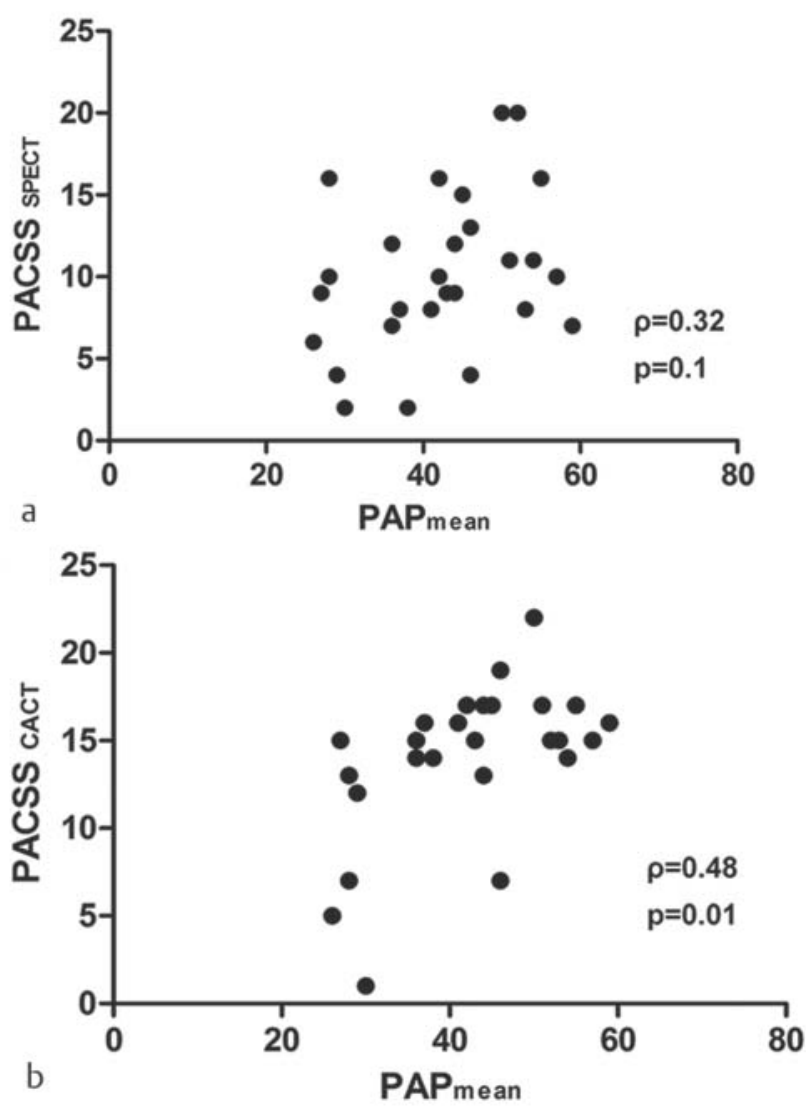

- Fig. 2 Correlation of the PAPmean to the PACSS SPECT $_{\text {and }}$ PACSS $_{\text {CACT. }}$. There is a correlation of the PAPmean to PACSS CACT, $_{\text {, }}$ whereas no correlation was seen for PACSS $\mathrm{SPECT}$, indicating a better CTEPH severity assessment of CACT. CACT $=$ C-arm computed tomography; SPECT = single photon emission computed tomography. - Abb. 2 Korrelation des pulmonalarteriellen Mitteldrucks mit dem PACSS SPECT $_{\text {und PACSS }}$ CACT $_{\text {. Korrelation des pulmonalarteriellen }}$ Mitteldrucks mit dem PACSS SPECT $_{\text {und PACSS }}$ CACT. Eine Korrelation zwischen pulmonalarteriellen Mitteldruck und PACSS SPECT $_{\text {zeigt sich }}$

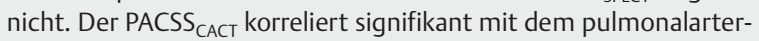
iellen Mitteldruck, was eine bessere Schweregradeinschätzung der CTEPH mit dem CACT nahelegt. CACT = C-Arm-Computertomografie; SPECT = Einzelphotonen-Emissionscomputertomografie.

\section{Results}

28 patients were enrolled in this study (23 men, 5 women, mean age $62.1 \pm 17.8$ years) with a $\mathrm{PAP}_{\text {mean }}$ of $42.1 \pm 10.0 \mathrm{mmHg}$ and a PVR of $656.3 \pm 337.7 \mathrm{dyn}^{*} \mathrm{~s} / \mathrm{cm}^{5}$.

Overall, 504 pulmonary artery segments were examined using SPECT and CACT. Both imaging modalities showed abnormalities suggestive of $C T E P H$ in all of the investigated patients who were thus detected to suffer from CTEPH. SPECT showed a PACSS range of 2 - 20 (median 10 [25/75 quartile: 7.75/13.5]) and CACT of 1 22 (median 15 [13.75/17]). PACSS SPECT $_{\text {and PACSS }}$ CACT were significantly correlated $(\rho=0.58, p=0.001)$. Concerning the treatment decision of the institutional CTEPH Board which assigned patients to a conservative (medical therapy, $n=10$ ) or an invasive (PEA and BPA, $n=18$ ) group, the PACSS ${ }_{\text {CACT }}$ median was significantly different $(p=0.04)$, whereas the median of PACSS ${ }_{S P E C T}$ lacked signifi- 
- Table 1 Inter-modality agreement of segmental findings observed in SPECT and CACT.

- Tab. 1 Übereinstimmung der Befunde zwischen den Modalitäten SPECT und CACT.

\begin{tabular}{|c|c|c|c|c|c|}
\hline & & \multicolumn{3}{|c|}{ SPECT } & \multirow[b]{2}{*}{ sum } \\
\hline & $K=0.38$ & normal & sub-segmental & segmental/occlusion & \\
\hline \multirow[t]{4}{*}{ CACT } & normal & 118 & 12 & 1 & 131 \\
\hline & sub-segmental & 145 & 161 & 23 & 329 \\
\hline & segmental/occlusion & 3 & 9 & 32 & 44 \\
\hline & sum & 266 & 182 & 56 & 504 \\
\hline
\end{tabular}

Contingency table of the findings assessed in corresponding pulmonary artery segments on SPECT and CACT. A kappa value greater than 0.81 was interpreted as excellent agreement, values of 0.61 to 0.80 were interpreted as good/substantial agreement, values of 0.41 to 0.60 as moderate agreement, values of 0.21 to 0.40 as fair agreement, and values less than 0.20 as poor agreement. $\mathrm{K}=$ Cohen's kappa value; $\mathrm{CACT}=\mathrm{C}$-arm computed tomography; SPECT = single photon emission computed tomography.Kontingenztabelle der CTEPH-typischen Befunde in den korrespondierenden Pulmonalarteriensegmenten im SPECT und in der CACT. Kappa-Werte größer als 0,81 wurden als exzellente, Werte zwischen 0,61 und 0,80 als gute/substantielle, Werte zwischen 0,41 und 0,60 als moderate, Werte zwischen 0,21 und 0,40 als schwache und Werte unter 0,20 als schlechte Übereinstimmung gewertet. $\mathrm{K}=$ Cohen's kappa; CACT = C-Arm-Computertomografie; SPECT = Einzelphotonen-Emissionscomputertomografie.

cance $(\mathrm{p}=0.06 ;$ - Fig. 1$) . \mathrm{PAP}_{\text {mean }}$ showed a significant difference between the two treatment groups (conservative: $36 \pm 8 \mathrm{mmHg}$; invasive: $46 \pm 9 \mathrm{mmHg} ; \mathrm{p}=0.02$ ). A mild correlation of elevated PAP $_{\text {mean }}$ and PACSS could be demonstrated for PACSS $(\rho=0.48, p=0.01)$, whereas no significant correlation was found for $\operatorname{PACSS}_{\text {SPECT }}(\rho=0.32, p=0.1$; Fig. 2 ).

SPECT detected 266/504 (53\%) arterial segments without and 238/504 (47\%) segments with V/Q mismatch, whereas CACT detected 131/504 (26\%) segments without abnormal findings and 373/504 (74\%) segments with findings indicating CTEPH. CACT showed 145 sub-segmental findings indicating CTEPH rated to be normal on SPECT. SPECT detected more segmental findings classified to be sub-segmental by CACT (23/504; $5 \%)$, whereas CACT detected fewer segmental findings rated sub-segmental by SPECT (9/504; 2\%; > Table 1). Sub-segmental findings on CACT consisted mostly of web-like stenoses and band-like structures in the pulmonary arteries. Two different examples of relevant discordant findings on SPECT and CACT are shown in $>$ Fig. 3,4 . The inter-modality agreement of SPECT and CACT was fair $(\kappa=0.38$; - Table 1). Phantom radiation measurements of thoracic CACT for male and female patients revealed an effective radiation dose for males of $1.81 \mathrm{mSv}$ and for females of $2.58 \mathrm{mSv}$.

\section{Discussion}

V/Q scintigraphy has been reported to be a valuable tool for excluding the diagnosis of CTEPH with a negative predictive value of nearly $100 \%[20,21]$. Nevertheless, studies comparing perfusion scanning and contrast-enhanced multi-detector computed tomography (MDCT) in patients suspected to suffer from CTEPH published sensitivity values for the detection of CTEPH with substantial variations $[4,20,21]$.

In 2007, Tunariu et al. reported a significantly higher sensitivity for V/Q scintigraphy of $97 \%$ compared to $51 \%$ for pulmonary MDCT [20]. These results demonstrate the insufficiency of tem- poral and spatial resolution obtained with the four-slice and eight-slice MDCT used at that time. The more recent prospective study of He et al., published in 2012, reported the substantially higher diagnostic sensitivity of $92 \%$ for CTEPH detection by pulmonary MDCT, while the sensitivity of $96 \%$ for $\mathrm{V} / \mathrm{Q}$ scintigraphy was similar [21].

Interestingly, Soler et al. reported a sensitivity of $62 \%$ for SPECT and $48 \%$ for MDCT for the detection of CTEPH vascular lesions on a pulmonary artery segment base compared to the gold standard of DSA imaging and histological specimens following PEA [4]. The latter result is a strong indicator that both methods may underestimate the extent of the disease. Not detecting pathologies with MDCT in the study of Soler et al. can be explained by the use of 4-row to 64-row scanners, thus resulting in a high variability of spatial resolution and an inferior pulmonary artery contrast enhancement compared to DSA $[4,8,9]$. In the case of SPECT, the missed findings might be explained by the assumption that web stenoses may not necessarily hinder tracer accumulation [4].

Digital subtraction angiography of the pulmonary arteries is still used for preoperative and pre-interventional work-up in CTEPH patients [6]. In two recent studies, additional CACT of the pulmonary arteries was shown to improve the diagnostic work-up of CTEPH patients and may be particularly useful prior to invasive treatment $[8,10]$. As thoracic CACT uses direct contrast medium injection into the pulmonary arteries, it combines features of DSA and MDCT [8 - 10]. Therefore, we attribute the higher number of abnormal imaging findings on CACT compared to those on SPECT to the following combination of DSA and MDCT imaging features, i. e., outstanding spatial resolution, local contrast medium administration, and $3 \mathrm{D}$ imaging of the pulmonary arteries and the surrounding anatomical structures. Moreover, CACT is not affected by the collateral systemic blood supply to the pulmonary vasculature, which is said to diminish the image quality of $\operatorname{MDCT}[22,23]$.

In our study, analyzing the added diagnostic value of contrastenhanced pulmonary artery CACT in patients with a positive ven- 

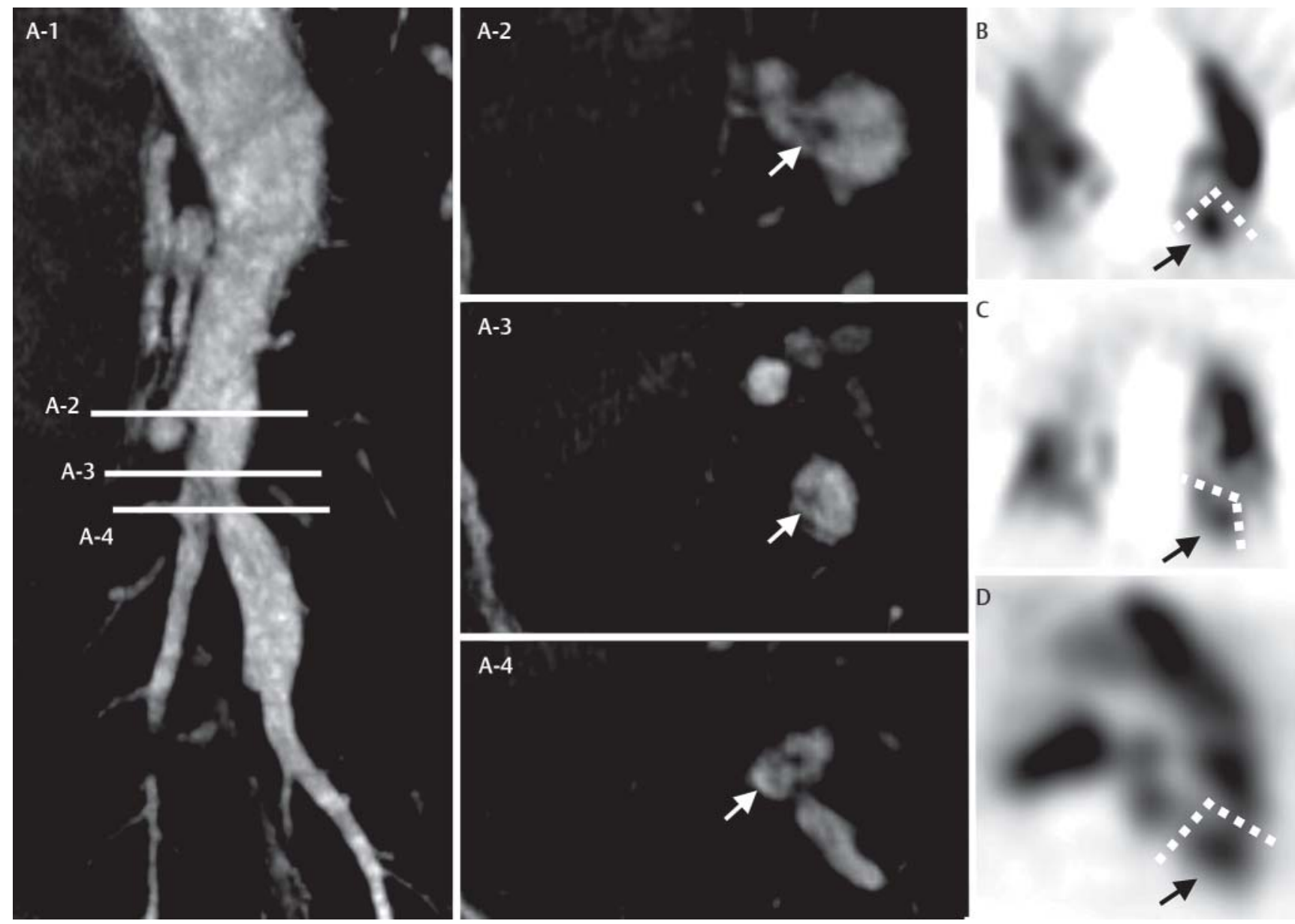

- Fig. 3 Example of discordant findings in CACT and SPECT. Images of a 65-year-old male patient with a baseline PAPmean of $44 \mathrm{mmHg}$ showing discordant findings in CACT and SPECT in the left lung. A-1 shows coronal reformation of the segment 10 artery of the left lung. A-2, A-3 and A-4 depict severe subsequent web-like stenosis in the branching of the segment 10 artery -indicating a complex CTEPH lesion (white arrows). B (axial), C (coronal) and D (sagittal) SPECT images of the same patient with no significant perfusion defect in segment 10 of the left lung (black arrows; dotted lines clarify the segment) - indicating that SPECT imaging is not able to display the complexity of the lesion. The patient was treated with BPA and his PAPmean decreased from $41 \mathrm{mmHg}$ to $26 \mathrm{mmHg}$ after 6 procedures. BPA = balloon pulmonary angiography, CACT = C-arm computed tomography; PAPmean = mean pulmonary artery pressure, SPECT = single photon emission computed tomography .

- Abb. 3 Beispiel von abweichenden Befunden zwischen CACT und SPECT. Bildbeispiel eines 65-jährigen Patienten mit unterschiedlichen Befunden in der CACT und der SPECT der linken Lunge. A-1 Koronare Reformatierung der Segment 10 Arterie links. A-2, A-3 und A-4 zeigen ausgeprägte netzartige Stenosen in der Aufzweigung der Segment 10 Arterie in die Peripherie (weiße Pfeile). B (axial), C (koronar) und D (sagittal) SPECT-Bilder des gleichen Patienten ohne Nachweis eines eindeutigen Perfusionsausfalls im Segment 10 links (schwarze Pfeile; gepunktete Linie zur Markierung des Segments 10 links). Der Patient wurde erfolgreich mittels mehrfacher BPA behandelt und sein pulmonalarterieller Mitteldruck hat von $44 \mathrm{mmHg}$ auf $26 \mathrm{mmHg}$ abgenommen. BPA = pulmonale Ballonangioplastie; CACT = C-Arm-Computertomografie; SPECT = Einzelphotonen-Emissionscomputertomografie.

tilation/perfusion SPECT mismatch pattern, CACT detected findings indicating CTEPH in $74 \%$ of the investigated segmental pulmonary arteries, whereas V/Q SPECT detected findings indicating CTEPH in $53 \%$. In 145 sub-segmental pulmonary arteries, CACT showed additional findings which were not detected by SPECT. The effective whole-body dose of ventilation/perfusion SPECT, as published by Stein et al. and in the guidelines of the European Association of Nuclear Medicine, was in a range of $1.2-2.0 \mathrm{mSv}$ [24, 25]. The effective radiation dose of thoracic CACT measured in our study was in a slightly higher range of $1.8-2.6 \mathrm{mSv}$, which is in an acceptable range when the additional findings are taken into account.
The main reason for detecting more sub-segmental lesions might be that small, intra-vascular webs and bands, underlying CTEPH and treatable by BPA in the pulmonary arteries do not substantially hinder blood flow and tracer accumulation. Therefore, SPECT may not be able to identify non-occlusive pathological findings. This hypothesis is supported by Dournes et al. who reported negative findings in V/Q scintigraphy and dual-energy CT-based iodine maps, while MDCT revealed obvious webs and bands in the particular pulmonary artery [12].

Hong et al. reported different perfusion patterns when comparing acute pulmonary embolism and CTEPH with the use of delayed dual-source $\mathrm{CT}$, thus indicating significant vascular remodeling in CTEPH patients [22]. As stated by Soler et al., CTEPH as 

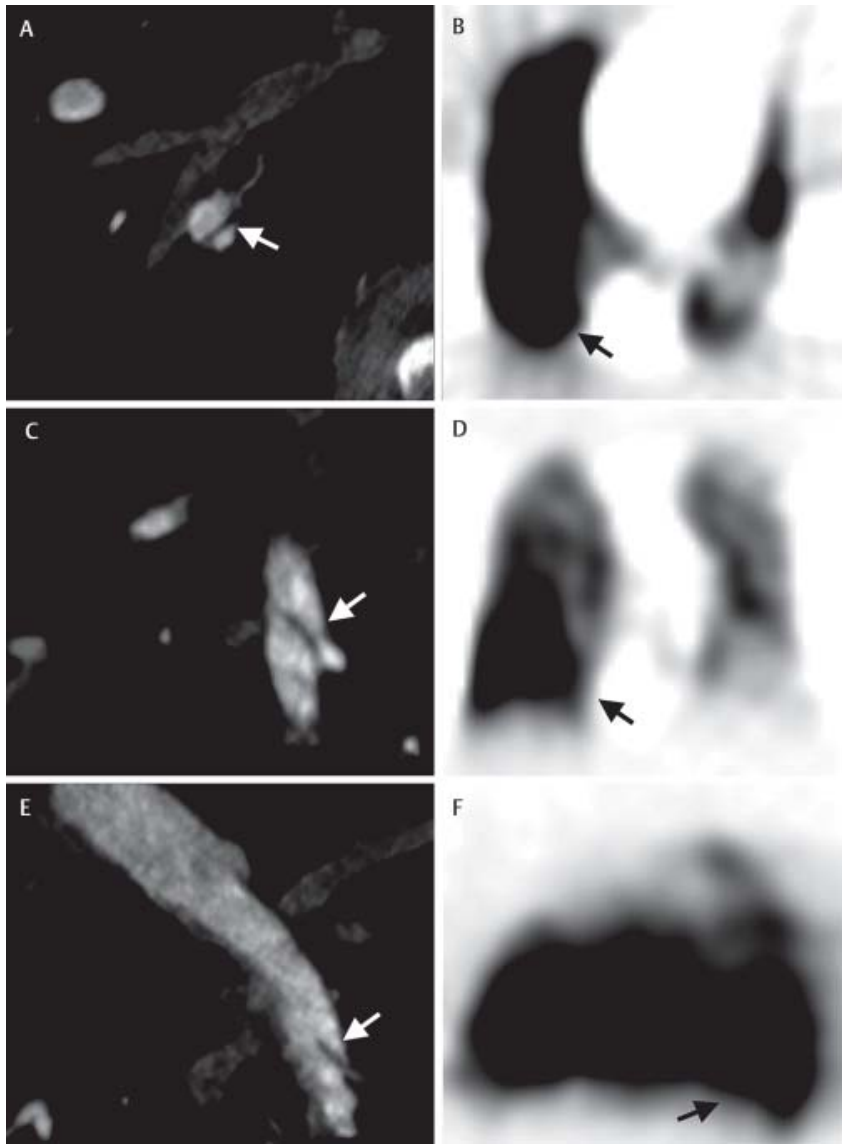

- Fig. 4 Example of discordant findings in CACT and SPECT. Images of a 78-year-old male patient with a baseline PAPmean of $46 \mathrm{mmHg}$ showing discordant findings in CACT and SPECT in the right lung. $\mathbf{A}$ (axial), $\mathbf{C}$ (coronal) and $\mathbf{E}$ (sagittal) depict a web-like stenosis in the segment 10 artery of the right lung (white arrows). B (axial), D (coronal) and $\mathbf{F}$ (sagittal) show corresponding SPECT images of the same patient without a perfusion defect in segment 10 of the right lung (black arrows). This patient is a potential candidate for BPA. BPA = balloon pulmonary angiography, $\mathrm{CACT}=\mathrm{C}$-arm computed tomography; PAPmean = mean pulmonary artery pressure, $\mathrm{SPECT}=$ single photon emission computed tomography.

- Abb. 4 Beispiel von abweichenden Befunden zwischen CACT und SPECT. Bildbeispiel eines 78-jährigen Patienten mit unterschiedlichen Befunden in der CACT und der SPECT der rechten Lunge. A (axial), $\mathbf{C}$ (koronar) und $\mathbf{E}$ (sagittal) Darstellung einer netzartigen Stenose in der Segment 10 Arterie rechts (weiße Pfeile). B (axial), D (koronar) und $\mathbf{F}$ (sagittal) korrespondierende SPECT-Bilder des gleichen Patienten ohne Nachweis von Perfusionsausfällen im Segment 10 rechts (schwarze Pfeile). Dieser Patient ist ein potentieller Kandidat für eine BPA. BPA = pulmonale Ballonangioplastie; $C A C T=C$ Arm-Computertomografie; SPECT = Einzelphotonen-Emissionscomputertomografie.

a chronic condition might allow the vessels to partially reperfuse, to redistribute blood flow, and to cause neo-vascularization of the pulmonary arteries [4]. These phenomena may also limit the value of SPECT perfusion scans for localizing CTEPH lesions [4].

The calculated PACSS for CACT showed a positive correlation with the mean pulmonary artery pressure. $\mathrm{PAP}_{\text {mean }}$ serves as an indicator of disease severity in CTEPH, as it reflects the hemodynamic consequences of chronic thromboemboli [18]. In concor- dance, a mildly significant difference of the median PACSS between the two patient groups undergoing either conservative or invasive treatment decided by the CTEPH Board was only detected for CACT. The CTEPH Board decision was based on a consensus including the SPECT imaging findings and invasive imaging as well as the clinical parameters and right heart hemodynamics. Both findings support the idea that the identification of additional vascular pathologies by CACT may not only provide more detail regarding the functional compromise, but may also translate into refined therapeutic decision-making. Whether this concept remains true in larger patient groups, whether the additional diagnostic information provided by CACT adds prognostic value to the identification of patients at an elevated risk, and how the information can be used to modify therapeutic decisions for the best possible outcome should be the subject of subsequent clinical trials.

Our study has several limitations. The small number of patients undergoing the different treatment strategies, especially BPA $(n=5)$, limited the ability to identify major statistically significant differences between the two imaging modalities. A direct comparison between CACT, SPECT, and histologic specimens would be an option to generate true sensitivity and specificity values, as shown by Soler et al. [4]. However, the direct correlation of imaging findings and histologic probes is only possible after PEA. One possibility of overcoming the difficulties with histologic probes might be a comparison of the investigated imaging modalities with supra-selective DSA, as acquired during pulmonary angioplasty [11]. Supra-selective DSA may also help to overcome the lack of a true reference standard to assess findings on the segmental and sub-segmental level of the pulmonary arteries in CACT [11], which is a limitation of our study.

Another limitation is the fact that the use of CACT was triggered by positive SPECT, which might lead to a referral bias. SPECT serves as a method for detecting potential CTEPH, and invasive imaging is used for confirming the diagnosis and characterization of the lesions. This may lower the impact of SPECT on the therapeutic decision. However, our study reflects clinical standards and the clinical routine and is, therefore, useful as an indicator of clinical relevance.

A further limitation of our study is the use of stand-alone SPECT. Previous studies have acknowledged that combined SPECT/CT imaging improves the specificity and overall diagnostic accuracy of lung scintigraphy, at least in patients with an acute pulmonary embolism [26, 27]. Another benefit of SPECT/CT compared to SPECT alone is the improved assignment of perfusion defects and lung segments [26, 27]. Therefore, a comparison of high-resolution CACT and high-resolution V/Q SPECT/CT examinations could be of additional clinical value and thus requires further examination.

\section{Conclusion}

In conclusion, V/Q SPECT of the lungs is a valuable tool to exclude $\mathrm{CTEPH}$. However, against the background of increasing diversity and challenging nuances in CTEPH treatment, CACT seems to provide added details for vessel characterization. This may be of importance for future clinical decision-making as pulmonary angioplasty represents a promising new treatment option targeting 
peripheral findings and making a more precise evaluation of the arterial pulmonary vasculature mandatory.

\section{CLINICAL RELEVANCE OF THE STUDY}

The rapidly increasing treatment options of CTEPH, especially $\mathrm{BPA}$, require an exact and comprehensive assessment of findings indicating CTEPH in the pulmonary vasculature for appropriate treatment planning. CACT has the potential to add significant diagnostic information to V/Q-SPECT-positive CTEPH patients concerning the clinical evaluation process and the final therapeutic decision.

\section{References}

[1] Kim NH, Delcroix M, Jenkins DP et al. Chronic thromboembolic pulmonary hypertension. J Am Coll Cardiol 2013; 62: D92-D99

[2] Hoeper MM, Madani MM, Nakanishi N et al. Chronic thromboembolic pulmonary hypertension. Lancet Respir Med 2014; 2: 573- 582

[3] Pengo V, Lensing AWA, Prins MH et al. Incidence of Chronic Thromboembolic Pulmonary Hypertension after Pulmonary Embolism. N Engl J Med 2004; 350: 2257-2264

[4] Soler X, Kerr KM, Marsh J] et al. Pilot study comparing SPECT perfusion scintigraphy with CT pulmonary angiography in chronic thromboembolic pulmonary hypertension. Respirology 2012; 17: 180-184

[5] Soler X, Hoh CK, Test V] et al. Single photon emission computed tomography in chronic thromboembolic pulmonary hypertension. Respirology 2011; 16: $131-137$

[6] Galiè N, Humbert M, Authors/Task Force Members et al. 2015 ESC/ERS Guidelines for the diagnosis and treatment of pulmonary hypertension: The Joint Task Force for the Diagnosis and Treatment of Pulmonary Hypertension of the European Society of Cardiology (ESC) and the European Respiratory Society (ERS)Endorsed by: Association for European Paediatric and Congenital Cardiology (AEPC), International Society for Heart and Lung Transplantation (ISHLT). Eur Heart J 2016; 37: 67-119

[7] Ogo T. Balloon pulmonary angioplasty for inoperable chronic thromboembolic pulmonary hypertension. Curr Opin Pulm Med 2015; 21: $425-431$

[8] Hinrichs JB, Marquardt S, Falck von C et al. Comparison of C-arm Computed Tomography and Digital Subtraction Angiography in Patients with Chronic Thromboembolic Pulmonary Hypertension. Cardiovasc Intervent Radiol 2016; 39: 53-63

[9] Hinrichs JB, Falck von C, Hoeper MM et al. Pulmonary Artery Imaging in Patients with Chronic Thromboembolic Pulmonary Hypertension: Comparison of Cone-Beam CT and 64-Row Multidetector CT. J Vasc Interv Radiol 2016; 27: 361.e2-368.e2

[10] Sugiyama M, Fukuda T, Sanda Y et al. Organized thrombus in pulmonary arteries in patients with chronic thromboembolic pulmonary hypertension; imaging with cone beam computed tomography. Jpn J Radiol 2014: $1-8$
[11] Fukuda T, Ogo T, Nakanishi $\mathrm{N}$ et al. Evaluation of organized thrombus in distal pulmonary arteries in patients with chronic thromboembolic pulmonary hypertension using cone-beam computed tomography. Jpn J Radiol 2016: 1 -9

[12] Dournes G, Verdier D, Montaudon M et al. Dual-energy CT perfusion and angiography in chronic thromboembolic pulmonary hypertension: diagnostic accuracy and concordance with radionuclide scintigraphy. Eur Radiol 2014; 24: 42 - 51

[13] Lang IM, Madani M. Update on chronic thromboembolic pulmonary hypertension. Circulation 2014; 130: 508 - 518

[14] Hinrichs JB, Renne J, Hoeper MM et al. Balloon pulmonary angioplasty: applicability of C-Arm CT for procedure guidance. Eur Radiol 2016: 1-8

[15] Boyden EA. The Nomenclature of the Bronchopulmonary Segments and Their Blood Supply: (As Revised by the Seventh International Congress of Anatomists, 1960). Chest 1961; 39: 1-6

[16] Werncke T, Falck von C, Luepke M et al. Collimation and Image Quality of C-Arm Computed Tomography: Potential of Radiation Dose Reduction While Maintaining Equal Image Quality. Invest Radiol 2015; 50: 514 521

[17] Charles MW. ICRP Publication 103: Recommendations of the ICRP†. Radiation Protection Dosimetry 2008; 129: 500 - 507

[18] Hoeper MM, Barbera JA, Channick RN et al. Diagnosis, Assessment, and Treatment of Non-Pulmonary Arterial Hypertension Pulmonary Hypertension. J Am Coll Cardiol 2009; 54: S85-S96

[19] Kundel HL, Polansky M. Measurement of Observer Agreement. Radiology 2003; 228: $303-308$

[20] Tunariu N, Gibbs SJR, Win Z et al. Ventilation-Perfusion Scintigraphy Is More Sensitive than Multidetector CTPA in Detecting Chronic Thromboembolic Pulmonary Disease as a Treatable Cause of Pulmonary Hypertension. J Nucl Med 2007; 48: 680-684

[21] He J, Fang W, Lv B et al. Diagnosis of chronic thromboembolic pulmonary hypertension: comparison of ventilation/perfusion scanning and multidetector computed tomography pulmonary angiography with pulmonary angiography. Nucl Med Commun 2012; 33: 459-463

[22] Hong Y], Kim JY, Choe KO et al. Different perfusion pattern between acute and chronic pulmonary thromboembolism: evaluation with twophase dual-energy perfusion CT. Am J Roentgenol 2013; 200: 812 - 817

[23] Willemink M], Van Es HW, Koobs L et al. CT evaluation of chronic thromboembolic pulmonary hypertension. Clinical Radiology 2012; 67: 277 285

[24] Stein PD, Woodard PK, Weg JG et al. Diagnostic Pathways in Acute Pulmonary Embolism: Recommendations of the PIOPED II Investigators 1. Radiology 2007; 242: 15-21

[25] Bajc M, Neilly JB, Miniati M et al. EANM guidelines for ventilation/perfusion scintigraphy: Part 1. Pulmonary imaging with ventilation/perfusion single photon emission tomography. Eur J Nucl Med Mol Imaging 2009; 36: $1356-1370$

[26] Gutte H, Mortensen J, Jensen CV et al. Detection of Pulmonary Embolism with Combined Ventilation-Perfusion SPECT and Low-Dose CT: Head-toHead Comparison with Multidetector CT Angiography. J Nucl Med 2009; 50: $1987-1992$

[27] Roach P], Gradinscak DJ, Schembri GP et al. SPECT/CT in V/Q Scanning. Seminars in Nuclear Medicine 2010; 40: 455-466 